УДК 330.113

DOI: 10.14451/1.181.60

\title{
ИНСТИТУТЫ ОБЕСПЕЧЕНИЯ ЭКОНОМИЧЕСКОЙ БЕЗОПАСНОСТИ НА ПРИМЕРЕ БАНКОВСКОЙ СФЕРЕ
}

\author{
(C) 2019 Рыжова Ирина Александровна \\ прикрепленное лицо на соискание ученой степени в Департаменте экономической теории \\ Финансовый университет при Правительстве РФ, Россия, Москва \\ E-mail: midnight-19@mail.ru
}

Современный этап мирового развития проявляет признаки перехода к многополярности, что сопровождается нестабильностью мировой экономики и ростом глобальной конкуренции. На экономические отношения между странами все больше влияние оказывают факторы, которые являются угрозой для экономической безопасности. Деятельность развитых государств нацелена на использование своих технологий, в частности информационных, в качестве инструмента глобальной конкуренции. Принимаемые иностранными государствами меры в области финансов, оказывают крайне негативное влияние на экономику России. Изучение банковской сферы и институтов ее экономической безопасности, является необходимым для стабильного развития страны и обеспечения экономической безопасности.

Ключевые слова: экономическая безопасность, банковская сфера, экономическая безопасность банковской сферы, институты, институциональное обеспечение экономической безопасности.

Экономическая безопасность страны основывается на нескольких сферах жизнедеятельности общества. К таким сферам можно отнести: продовольственную сферу, информационную сферу, банковскую сферу и т.д. Все эти сферы в равной степени оказывают значительное влияние на экономическую безопасность страны. Это связано с тем, что они содержат в себе неотъемлемые компоненты стабильной жизни в современном обществе. При сбоях в процессах любой их этих сфер страна может оказаться в глубоком кризисе. Ярким примером такого кризиса может служить банкротство Lehman Brothers (Лемон Бразерз) в 2008 году [11]. Более того, институты экономической безопасности, чаще всего, применимы к разным сферам экономики (Уголовный Кодекс, Антимонопольное законодательство, законе о рекламе и т.д.).

Банковская сфера является основной сферой для экономической безопасности страны. Сфера банковской деятельности давно перестала включать в себя только те отношения, которые строятся между кредитными организациями и физическими/юридическими лицами. По мнению автора, современная банковская сфера включает в себя и финансовые отношения. Под банковской сферой автор понимает деятельность всех участников банковской системы по созданию и предоставлению своих услуг.

При этом количество участников банков- ской сферы также увеличилось. Понятие «банковская сфера» на сегодняшнем этапе развития включает в себя не только Центральный Банк и кредитные организации, а также представительства иностранных банков [1], но и других участников: органы государственной власти, небанковские кредитные организации, некредитные банковские организации и т.д. Это связано с ростом глобализации, расширение банковских операций, повышение уровня экономической безопасности, с цифровизацией бизнеса и экономики. Вместе с этим происходит рост рисков и угроз.

Условно, безопасность банковской сферы необходимо изучать на трех уровнях: 1) внутри самой организации; 2) взаимодействие между кредитной организаций и другими участниками банковской сферы (например, с органами государственной власти); 3) отношения между банковской сферой страны с участниками мировой экономики (например, с Международным Валютным фондом или с экономиками других стран). При этом угрозы и риски экономической безопасности возникают на каждом уровне отношений.

Выявление и предупреждение всех угроз происходит с помощью множества институтов, которые регулируют экономическую безопасность. Под институтом автор понимает формальные и неформальные нормы. В данной 
статье нас интересуют формальные нормы, которые исполняются органами государственной власти или организацией, которая их принимает.

Изучив государственные нормативно-правовые акты в банковской сфере на протяжении последних 30 лет, можно сделать вывод, что обеспечение ее экономической безопасности происходило стихийно и непродуманно. Сложность работы с банковскими институтами заключается в огромном числе норм и правил, в слож- ностях их механизма внедрения и исполнения. Условно в зависимости от области их влияния на экономику, можно разделить институты экономической безопасности по сферам влияния (таблица 1).

Как видно из таблицы 1 институты построены таким образом, чтобы охватить все области деятельности участников банковской сферы. Построение институтов экономической безопасности банковской сферы предназначены для

Таблица 1. Институты обеспечения экономической безопасности в банковской сфере

\begin{tabular}{|c|c|c|c|}
\hline Сфера влияния & Институт & $\begin{array}{c}\text { Механизм } \\
\text { реализации }\end{array}$ & $\begin{array}{c}\text { Проблемы и } \\
\text { несовершенства }\end{array}$ \\
\hline $\begin{array}{l}\text { Область снижения } \\
\text { рисков }\end{array}$ & $\begin{array}{l}\text { Ф3 № 177-Ф3 (ред. } \\
\text { от 28.11.2018) «О } \\
\text { страховании вкладов } \\
\text { в банках Российской } \\
\text { Федерации» }\end{array}$ & $\begin{array}{l}\text { Агентство по } \\
\text { страхованию } \\
\text { вкладов, опционы, } \\
\text { свопы и т.д. }\end{array}$ & $\begin{array}{l}\text { Несовершенство } \\
\text { рынка производных } \\
\text { финансовых } \\
\text { инструментов, } \\
\text { отсутствие в России } \\
\text { доверия в бирже }\end{array}$ \\
\hline $\begin{array}{l}\text { Открытость } \\
\text { (транспорентность) } \\
\text { финансового рынка }\end{array}$ & $\begin{array}{l}\text { Ф3 № 222-Ф3 «О } \\
\text { деятельности } \\
\text { кредитных } \\
\text { рейтинговых } \\
\text { агентств } \\
\text { Российской } \\
\text { Федерации .... } \\
\end{array}$ & $\begin{array}{l}\text { Рейтинговые } \\
\text { агентства }\end{array}$ & $\begin{array}{l}\text { Ошибки персонала в } \\
\text { подсчетах рейтингов; } \\
\text { не объективность } \\
\text { агентств; высокая } \\
\text { зависимость } \\
\text { эмитента и т.д. }\end{array}$ \\
\hline $\begin{array}{l}\text { Информированность } \\
\text { участников сферы }\end{array}$ & $\begin{array}{l}\text { Ф3 № 218-Ф3 (ред. } \\
\text { от 01.05.2019) «О } \\
\text { кредитных } \\
\text { историях» }\end{array}$ & Кредитные бюро & $\begin{array}{lrr}\text { кредитные } & \text { бюро } \\
\text { работают } & & \text { с } \\
\text { определенными } & \\
\text { банками и } & \text { не } \\
\text { обладают } & & \text { всей } \\
\text { информацией } & \text { в } & \text { всех } \\
\text { клиентах } & & \end{array}$ \\
\hline $\begin{array}{l}\text { Сфера деятельности } \\
\text { участников } \\
\text { банковских } \\
\text { процессов }\end{array}$ & $\begin{array}{l}\text { Федеральный закон } \\
\text { от } 10.07 .2002 \text { № 86- } \\
\text { Ф3 «О Центральном } \\
\text { банке Российской } \\
\text { Федерации» }\end{array}$ & $\begin{array}{l}\text { ЦБ } \\
\text { Внешэкономбанк, } \\
\text { Агентство по } \\
\text { страхованию } \\
\text { вкладов }\end{array}$ & $\begin{array}{l}\text { Несовершенство } \\
\text { институциональной } \\
\text { базы РФ; сложности } \\
\text { контроля }\end{array}$ \\
\hline $\begin{array}{l}\text { Органы власти, } \\
\text { регулируюшие } \\
\text { деятельность } \\
\text { участников }\end{array}$ & $\begin{array}{l}\text { Уголовный Кодекс } \\
\text { РФ, } \\
\text { Антимонопольное } \\
\text { законодательство и } \\
\text { т.д. }\end{array}$ & $\begin{array}{l}\text { ФАС, Уголовно- } \\
\text { исполнительная } \\
\text { система и т.д. }\end{array}$ & $\begin{array}{l}\text { Несоразмерность } \\
\text { наказания } \\
\text { преступления, } \\
\text { несовершенство } \\
\text { механизма } \\
\text { исполнительной } \\
\text { власти и т.д. } \\
\end{array}$ \\
\hline $\begin{array}{l}\text { Сфера } \\
\text { взаимодействия } \\
\text { банковской сферы и } \\
\text { финансовых рынков }\end{array}$ & $\begin{array}{l}\text { Законодательство в } \\
\text { области } \\
\text { синдицированного } \\
\text { кредитования, } \\
\text { Паевых } \\
\text { инвестиционных } \\
\text { Фондов и т.д. } \\
\end{array}$ & Московская биржа & $\begin{array}{lrr}\text { Сложный } & \text { вход } & \text { и } \\
\text { выход к } & \text { данному } \\
\text { рынку } & & \text { для } \\
\text { потенциальных } & \\
\text { участников } & \end{array}$ \\
\hline
\end{tabular}

Источник: составлено автором 
защиты участников от угроз и рисков. Институты экономической безопасности банковской сферы связаны между собой, также как и участники банковской сферы. В каждом нормативноправовом акте участникам банковской сферы предписаны максимально допустимые границы при совершении операций в рамках своих лицензий.

Тем не менее, кроме предложенной классификации и рассмотренных законодательных актов существует и те, которые регулируют банковскую деятельность косвенно. Например, закон о рекламе [2]. В нем указано, какие банковские продукту можно рекламировать, какие слова и гарантии можно описывать. При этом банкам необходимо называть номер своей лицензии. Мониторинг банковской рекламы проводит и Федеральная антимонопольная служба. K сожалению, вместо того чтобы контролировать достоверность рекламы формально происходит контроль только за соблюдением предоставления соответствующей лицензии.

Более того, в основном нормативно-правовом акте, на который следует ориентироваться при изучении экономической безопасности, выступает Указ Президента «О Стратегии экономической безопасности Российской Федерации на период до 2030 года» вообще нет информации об обеспечении экономической безопасности в банковской сфере. При этом Центральный банк РФ является не только исполнительным органом для устранения всех вызовов и угроз, но и проверяющим органом, который следить за исполнением всех необходимым мер.

Данное положение Банка России говорит о том, что все сферы жизнедеятельности государства тесно связаны между собой. Особенно на данном этапе развития экономики между собой связаны банковская и информационная сфера. Информационная сфера или сфера цифровых технологий сейчас активно становится основной площадкой для совершения финансовых операций. Банковские операции при взаимодействии с цифровыми технологиями способствуют росту обмена и потребления финансовых и денежных ресурсов. При этом, способы взаимодействия перестали требовать личного присутствия: для совершения операций достаточно воспользоваться банкоматом или приложение на телефоне. Технологии достигли такого уровня, что для оплаты покупок достаточно воспользоваться мобильным телефоном, а в некоторых странах кольцом или часами, с встроенной системой NFC.

Однако вместе с ростом цифровых технологий, увеличился и рост преступности, связанный с мошенничеством и вымогательством денег. Для совершения мошеннических действий сейчас не обязательно взламывать социальные сети и личные кабинеты. Сейчас появились дебетовые карты с бесконтактной оплатой. Такой же системой обладают и современные мобильный телефоны. Мошенникам достаточно приложить терминал к карману или сумке, где лежит телефон или карта, и произойдет списание денежные средства.

Самый популярный вид мошенничества - вишинг, или голосовой фишинг. Мошенники звонят якобы от лица банка и сообщают, что с карты клиента хотели провести списание и просят назвать личные данные, чтобы попасть в личный кабинет клиента. В виду низкой финансовой грамотности мошенники могут рассчитывать на большую прибыть. Такая же ситуация возникает и с рассылкой по электронной почте, когда клиенту приходит письмо якобы из банка. Переход по ссылке может автоматически включить процесс скачивания вредоносных программ или попросит внести личные данные. Данных мошенников очень сложно вычислить и призвать их к ответственности именно потому, что механизмы противодействия преступникам в цифровой сфере слабо развиты.

В России сфера информационной и цифровой безопасности, как для клиентов банков, так и для самих кредитных организаций, находится под постоянной угрозой. Отсутствие финансовой грамотности у населения приводит к тому, что пользователи добровольно отдают свои деньги мошенникам. Основная проблема заключается в том, что у органов следствия отсутствуют как специальная техника, так и специальный уровень подготовки кадрового состава. Более того, в России слабо финансируется отрасль расследования именно цифровых преступлений. Другими словами отсутствует механизм реализации институтов, направленных как на защиту участников, так и на поиск и поимку преступников.

Не смотря на то, что активно происходит цифровизация экономики, в России институциональная обеспеченность экономической безопасности в этом направлении еще только развивается. Экономические преступления с помощью ИТ-технологий происходят быстрее, чем 
развивается системы экономической безопасности в этой области. Чаще всего преступники в цифровой среде остаются неопознанными, что препятствует их поимке. Это говорит о том, что необходимо дорабатывать механизмы обеспечения экономической безопасности не только с помощью изменения законодательной базы, но и в области подготовки персонала и оборудования.

У кредитных организаций также существуют определенные проблемы обеспечения своей экономической безопасности. В первую очередь проблемы происходят при исполнении законодательных актов. С одной стороны, Кредитные организации и другие участники банковской сферы обязаны самостоятельно заниматься обеспечение своей экономической безопасности. С другой стороны, законом установлено, что системы безопасности должны приобретаться у сторонних подрядчиков, а физическая охрана через ЧОП. Однако банк перестраховывается, и происходит двойная степень охраны: своя и со стороны других организаций. При этом законами не регулируется уровень защищенности, нет регламента, который оценивает защищенность в процентном соотношении и т.д. Всем этим занимается сама организация.

Помимо этого, институциональная среда экономической безопасности нацелена на «зачистку» участников банковской деятельности. Об этом могут служить такие показатели как увеличение уставного капитала банка, разделение лицензий, увеличение требований к проводимым операциям, ужесточение необходимых требований для выдачи лицензии и т.д. За несоблюдение требований Центральный Банк отзывает лицензии по причинам нарушения законодательства о противодействии легализации преступных доходов и финансированию терроризма.

Тем не менее, происходит развитие систем платежей и переводов денежных средств. Так, например, в 2018 году была запущена Система быстрых платежей. Данный сервис позволит клиентам переводит свои денежные средства в любой банк по номеру телефона. Единственным условием является подключение банков к Системе. Однако пока не понятно, как будет происходить обеспечение безопасности таких операций, ведь клиент не может отменить платеж или перевод средств, даже если доказано, что действия совершены в ходе мошеннической операции.
Обеспечение экономической безопасности самих клиентов также является проблемой институциональной среды. Государство охраняет клиентов, но только в депозитной части и не превышающей один миллион 400 тысяч рублей. Это происходит благодаря деятельности Агентства по страхованию вкладов. Также клиенты защищены с помощью внутрибанковской системы безопасности. И на этом все. Банковские организации даже не всегда информируют своих клиентов о действиях современных мошенников.

Так, например, сейчас очень популяр факт мошенничества с банкоматами. Мошенник специально создает большую очередь, медленно работает с банкоматом, вводит данные для пополнения номера мобильного телефона с помощью банковской карты или наличных и не завершает операцию. Когда он уходит, следующий в очереди человек вставляет свою банковскую карту в терминал, с которой тут же списывается сумма. После этого деньги с телефона мошенника выводятся через электронные кошельки. Дело в том, что на экране терминала присутствует надпись «чтобы завершить оплату используйте карту или устройство». По закону банк не нарушает закона «О безопасности», поэтому претензий к банку клиент не может высказывать. Единственное, что предпринимает банк в таких случаях - это советует клиентам быть внимательнее и обращать внимание на экран терминала и банкомата перед использованием.

Другими словами физические лица практически не защищены от потери или утраты своих денежных средств. Основное их средство защиты - внимательность и финансовая грамотность. у физических лиц практически нет возможностей обеспечить свою безопасность. Они не имеют права отменять платежи, не могут по своей собственной инициативе предотвратить перевод или платеж, даже если он был совершен минуту назад. Но при этом российское общество страдает от перекредитованность населения. По данным Центрального Банка 43\% всех заемщиков получают зарплату до 30 тысяч рублей [5] и при этом имеют признаки закредитованности.

Чтобы снизить рост кредитования Центральный Банк вводит дополнительные коэффициенты и надбавки за предоставление необеспеченных кредитов и, тем самым, высокорисковых. Однако проблема для банков при выдаче кредитов намного шире, чем кажется. Чаще кредиты выдаются гражданам, которые уже имеют за- 
крытый или непогашенный кредит, а вот клиенты, которые ранее не брали на себя финансовые обязательства, поучают отказ. Такие клиенты в глазах банков не являются привлекательными, то есть они не проходят скоринговую оценку выдачи клиентов. А это говорит о том, что скоринг настроен неправильно. Скоринговые системы привязаны к бюро кредитных историй. Это может быть Национальное бюро кредитных историй или другие. Проблема заключается в том, что нельзя быть уверенным, что клиент, которого проверяет система, есть в этой базе и что информация о нем полная. Передавать данные о своих клиентах в бюро кредитных историй банки обязаны, но в какое именно бюро передавать - банк решает сам. Так и получается, что банк, который дает кредит, может обратиться в бюро, в котором информации о клиентах нет или она не полная. Скоринговое принятие решений помогает банкам быстро определить вопрос выдачи ссуды, но она не может рассчитать вероятность закрытия этого кредита или того, что клиент не будет платить.

Сфера ИТ-технологий неразрывно связана с современным денежным оборотом. Исключить одну сферу из другой уже невозможно. Но и изучать одну сферу без другой неактуально. На данном этапе развития экономики и общества существует необходимость в комплексном изменении институциональной обеспеченности в области экономической безопасности. В случае с банкоматами, например, необходимо создавать такие процедуру, при которых при оплате или пополнение счетов будет необходимо сначала внести карту или деньги, а уже потом выполнять операции. Или придумать другие методы, при которых мошенничество будет невозможным. В любом случае кредитные организации должны применять какие-то реальные действия, направленные на борьбу с мошенниками, которые пользуются несовершенством проводимых банковских операций. Более того, в законодательной области и в области расследований также необходимо вносить кардинальные изменения, которые будут способствовать не только предупреждению мошеннических действий, но и которые после совершения преступления смогут оперативно найти и арестовать преступников.

\section{Библиографический список}

1. О банках и банковской деятельности [Федеральный закон от 02 декабря 1990 г. № 395-1-Ф3] [Электронный ресурс] // КонсультантПлюс.- Режим доступа: http://www.consultant.ru/document/cons_doc_LAW_5842/ (дата обращения: 02.11.2019).

2. О рекламе [Федеральный закон от 13.03.2006 № 38-Ф3] [Электронный ресурс] // КоонсультантПлюс.- Режим доступа: http://www.consultant.ru/document/cons_doc_LAW_58968/ (Дата обращения: 20.11.2019).

3. Адамчук, О. Путин закрутит банки. Владимир Путин поддержал сокращение числа банков / О. Адамчук. [Электронный ресурс].- Режим доступа: https://www.gazeta.ru/business/2014/01/22/5860517.shtml (дата обращения: 29.11.2019).

4. Банковская система: «реформирование» или «модернизация»? [Электронный ресурс].- Режим доступа: https://www.banki.ru/news/interview/?id=27131 (дата обращения: 18.11.19).

5. Бедные россияне берут все больше кредитов. Центробанк обеспокоен [Электронный ресурс].- Режим доступа: https://www.bbc.com/russian/news-47868541 (дата обращения: 18.11.19).

6. Журило, П.П. Механизм обеспечения экономической безопасности Российской Федерации в современных условиях // ARS ADMINISTRANDI. 2012. № 4. С. 71. [Электронный ресурс].- Режим доступа: https:// cyberleninka.ru/article/n/mehanizm-obespecheniya-ekonomicheskoy-bezopasnosti-rossiyskoy-federatsii-vsovremennyh-usloviyah (дата обращения: 15.11.2019).

7. Обзор результатов обобщения и анализа правоприменительной практики контрольно-надзорной деятельности федеральной службы по финансовому мониторингу за 2018 год. [Электронный ресурс] // Электронный фонд URL: http://docs.cntd.ru/ (дата обращения: 19.11.2019)

8. Официальный сайт Центрального Банка России [Электронный ресурс] - Режим доступа: https://www.cbr. ru/today/bankstatus/ (дата обращения 09.06.2019).

9. Ситнова, И.А. Сущность и структура институциональной среды экономики современной России: возможность перехода на интеллектуальное развитие/ И.А. Ситнова, Д.У. Ишназаров, З.М. Салихова // Экономическое возрождение России. 2014. № 3 (41). С. 83-84.

10. Шагиев, Э.Р. Экономическая безопасность России /Э.Р. Шагиев, С.В. Коптякова // Актуальные проблемы современной науки, техники и образования. МГТУ им. Г.И. Носова (Магнитогорск) -2010.

11. Lehman Brothers рухнул по схеме [Электронный ресурс].- Режим доступа: https://www.kommersant.ru/ doc/1337156 (дата обращения: 18.11.19). 